\title{
The Shift to East: China, US Dollar, and the New Multipolar World ${ }^{1}$
}

\author{
Miriam L. Campanella
}

"At no time in modern history have so many developing countries been at the forefront of a multipolar economic system. (..)Within the next two decades, the rise of emerging economies will inevitably have major implications for the global economic and geopolitical landscape" 2 .

Geo-economics literature has largely anticipated that the world's economic center of gravity is shifting East. Yet how quick this seems to be happening, and what geo-political consequences this development is set to generate in the current international system, still raise surprise and concern. After describing in a glimpse what the shift of the economic center of gravity really means, I will make some observations on why the new economic realities have not yet changed the current financial and monetary international order, which sees the US dollar to still be the king. In a pioneering study $(2012)^{3}$ on the economic impact of urbanization, the McKinsey Global Institute gauged how the center of gravity, in motion since the year $1 \mathrm{AD}$ and likely to move until 2025, is rapidly shifting East, at a speed of 140 kilometers a year, a faster speed than ever before in humanhistory.

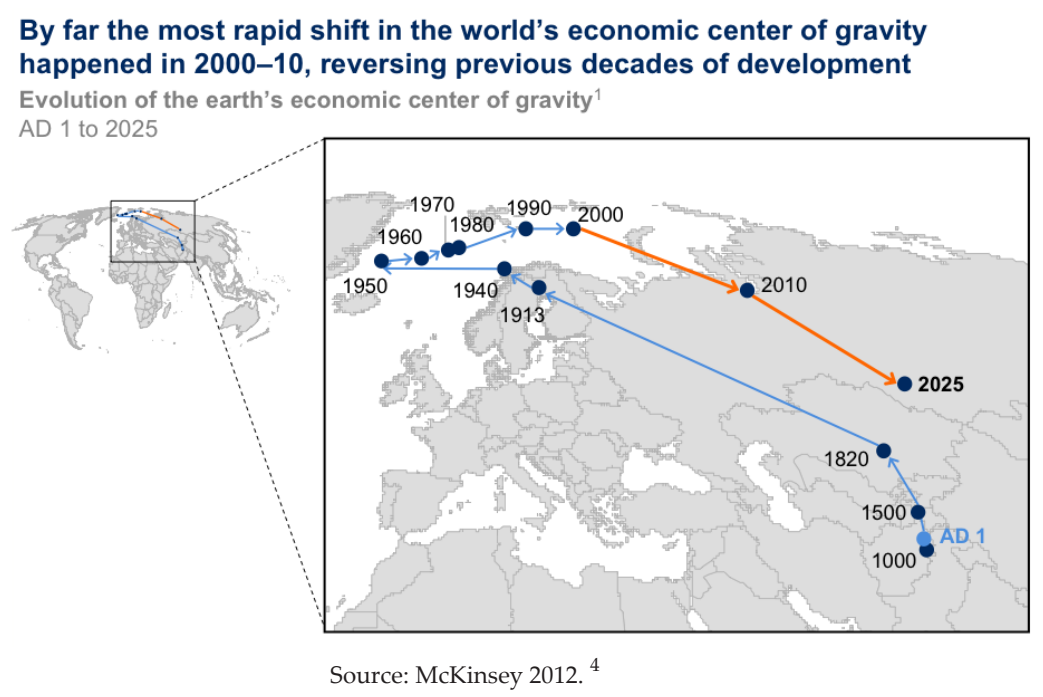

The most striking aspect of the map is the boomerang-like path of the center of gravity. From the days of the Roman Empire through the middle of the $20^{\text {th }}$ century, the center of gravity moved west.
For centuries, China, India, and southeast Asia were some of the biggest economic powerhouses in the world, and the westward shift only accelerated during and after the Industrial Revolution in Europe and North America. 
Since the mid-20 th century, with the rise of emerging markets in Asia and elsewhere, the center has begun to shift back to the East and South.

If McKinsey's projections about demographics and growth in the next few years are correct, that shift will only continue and accelerate as emerging and developing markets continue to grow rapidly, while developed markets grow at a much slower pace.

The rapid urbanization in developing countries, in particular China, the advance of local middle classes, and the creation of new "middleweight cities" are identified as the drivers of the shift. In a successive report, McKinsey identifies 600cities worldwide making the largest contribution to a higher global GDP, covering nearly 65 percent of the world economic growth by 2025.Yet, the most dramatic story within the City 600 reveals that just over 440 cities will be located in emerging economies.

According to McKinsey, "by 2025 the Emerging 440 will account for close to half of the overall growth. One billion people will enter the global consuming class by 2025. They will have incomes high enough to classify them as significant consumers of goods and services, and around 600 million of them will live in the Emerging 440".

China's urbanization has seen, in just one generation, around 300 million people passing from rural subsistence farming to urban industrial and technology-rich jobs. At least 13 new cities with a population of over 10 millions are new cities and 19 "super city" clusters are underway, strengthening the links between them. HSBC of London expects that $80 \%$ of Chinese GDP will come from those cities.

China plays the role of both an accelerator and a role model. A case in point is Shenzhen. In 1980, it was home to 30.000 fishing people. Today, it produces $90 \%$ of the world's electronics and is home to over 12.5 million people. It has 3 million registeredbusinesses. Itiscompounding its growth at over $12 \%$ a year, doubling in the last six years. With nearly 70 million people and
\$1.5 trillion GDP, it is economically bigger than Australia or Mexico. Guangdong (in China's mainland part) alone exported $\$ 670$ billion in goods last year. Three of the world's ten busiest container ports are in the region.

Connectivity and infrastructure play as keyfactors in consolidating and forwarding the growth of the new center of economic gravity. A decade ago, China was still building its first extensive high-speed train line.Today,no country has more miles of high-speed rail in service. At $26,869 \mathrm{~km}(16,696 \mathrm{mi})$, China accounts for $65 \%$ of the 41,222 km (25,614 mi) of high-speed rail in operation worldwide. In 2015, 800 million riders - or half of the global total - used highspeed rail in China. A further 10,738 km (6,672 $\mathrm{mi}$ ) is currently under construction in China. That expansion alone is slightly more than the total combined length of the next four longest high-speed systems in the world (Japan, Spain, France and Germany). China's first high-speed rail line began service in 2011. It links Beijing and Shanghai and is $1,318 \mathrm{~km}$ (819 miles) long. This connection reduced the train travel time between these two cities from ten hours tojust five hours. Its top speed is $350 \mathrm{~km}$ per hour. The Chinese government is determined to have its high-speed rail network covering large parts of the country. As of 2014, the Lanzhou-Xinjiang line covers a distance of 1,785 km (1,109 miles) from central China to remote western regions. Lanzhou was historically a Silk Road hub at one time. The trains today travel at up to $250 \mathrm{~km}$ per hour and have protection barriers against desert winds (The Globalist, 2018)

\section{Additional Remarks}

A growing amount of literature confirms that the center of economic gravity is moving East, and the process is strengthening the Asian economies.

Yet, in contrast to the above picture, questions arise over whether the current international financial and monetary system still revolves around the US dollar, which still plays a 
dominant role. What are the gravitational forces that still play in favor of the dollar? The response is well articulated in a speech by Claudio Borio. "The dollar exerts a powerful gravitational force on other currencies, as judged from how currencies move in relation to each other. Based on statistical techniques that seek to single out this effect, if one considers the euro and the yen as the other possible reference currencies, and uses GDP as weights, the "dollar zone" was, again, around $60 \%$ in 2014, the euro was second at only $25 \%$ and the yen a distant third. This gravitational pull, in turn, has a deep influence on the denomination of countries' assets and liabilities and, hence, also on FX reserve composition, as it determines a portfolio's sensitivity to exchange rate fluctuations. There is a clear positive relationship across countries between these shares and the degree to which they co-move with the dollar". ${ }^{5}$ In the end, Borio concludes that the irresistible gravitational force of the dollar comes from foreign exchange reserves and the US' large share of world GDP: "the entire world is still in the dollar zone".

The sheer size of the US economy, which is just around $22 \%$ of total global GDP, just a notch higher than China's, offers a weaker explanation of the gravitational pull towards the dollar. A more significant feature is likely to come from the US huge trade imbalance, due mostly to the US economy having played as "the consumer of last resort", and the behavior of central banks in emerging economies busy to buy, with their receipts from exports, US Treasury Bonds (T-Bonds). Since the Asian Crisis (1997-98), Asian export-led economies and especially China have accumulated large amounts of dollars, which they have redeployed in US-Treasury Bonds(T-Bonds) in order to defend the foreign exchange value of their national currencies. Acquiring largeamount of T-Bonds, the emerging economies in Asia have generated a strong gravitational force towards the dollar.By sitting on \$3.3 trillion of foreignexchange reserves, China alone is the US largest creditor.

Things, though, are changing. The controversial tradepolicyinitiatedbyTrump'sAdministration, aimed at shrinking imports and relaunching America's Manufacturing Renaissance, is set to have critical consequences on the dollar's dominance. It likely will reduce trade deficit, moreover will reduce the circulation and holdings in US dollar. In the end, these developments are set to materialize a multipolar monetary system.

1. In this context, the moves of the People's Bank of China to internationalize the use of the renminbi (RMB) and its admission into the IMF's Special Drawing Rights, are consequential to the new multi-polar monetary regime. The growth of RMB-based trade and settlements has made the RMB Asia's new reference currency, close to surpass the US dollar. These developments are mostly due to the effects of the financial crisis and have been supported by the region's economic and financial integration. As a reference currency of necessity or choice, the emergence of the RMB in Asia is set to weaken the current global dominance of the US dollar.

2. In conclusion, the growth of the RMB as an international currency, and a stronger circulation of the euro, are pointers of a multipolar currency system, which will balance and distribute responsibilities in a better way than the current unipolar currency regime. ${ }^{6}$

\footnotetext{
${ }^{1}$ This note draws on the author's presentation "Flussi e centri finanziari: una nuova geografia mondiale" at Collegio Carlo Alberto, Turin (Italy) 18-06-2018. http://triffininternational.eu/other-activities/conferences/1242-flussi-e-centri-finanziari-una-nuova-geografia-mondiale

${ }^{2}$ Multipolarity: The New Global Economy. World Bank Group. Washington DC, (2011)

${ }^{3}$ Urban world: Cities and the rise of the consuming class, McKinsey Global Institute, (2012)

${ }^{4}$ McKinsey Global Institute, op. cit.

${ }^{5}$ Claudio Borio, Pluralism, more stability?, Bank for International Settlements https://www.bis.org/speeches/sp160510_slides.pdf

${ }^{6}$ Miriam L. Campanella, The internationalization of the Renmimbi and the rise of a multipolar currency system, ECIPE WORKING PAPER, No. 01/2014
} 